\title{
Adding a statin to a combination of ACE inhibitor and ARB normalizes proteinuria in experimental diabetes, which translates into full renoprotection Carla Zoja, Daniela Corna, Elena Gagliardini, Sara Conti, Lorenzo Arnaboldi, Ariela Benigni and Giuseppe Remuzzi \\ Am J Physiol Renal Physiol 299:F1203-F1211, 2010. First published 18 August 2010; \\ doi:10.1152/ajprenal.00045.2010
}

You might find this additional info useful...

This article cites 55 articles, 29 of which can be accessed free at:

http://ajprenal.physiology.org/content/299/5/F1203.full.html\#ref-list-1

Updated information and services including high resolution figures, can be found at:

http://ajprenal.physiology.org/content/299/5/F1203.full.html

Additional material and information about AJP - Renal Physiology can be found at: http://www.the-aps.org/publications/ajprenal

This infomation is current as of April 22, 2011.

AJP - Renal Physiology publishes original manuscripts on a broad range of subjects relating to the kidney, urinary tract, and their respective cells and vasculature, as well as to the control of body fluid volume and composition. It is published 12 times a year (monthly) by the American Physiological Society, 9650 Rockville Pike, Bethesda MD 20814-3991. Copyright @ 2010 by the American Physiological Society. ISSN: 0363-6127, ESSN: 1522-1466. Visit our website at http://www.the-aps.org/. 


\title{
Adding a statin to a combination of ACE inhibitor and ARB normalizes proteinuria in experimental diabetes, which translates into full renoprotection
}

\author{
Carla Zoja, ${ }^{1}$ Daniela Corna, ${ }^{1}$ Elena Gagliardini, ${ }^{1}$ Sara Conti, ${ }^{1}$ Lorenzo Arnaboldi, ${ }^{2}$ Ariela Benigni, ${ }^{1}$ \\ and Giuseppe Remuzzi ${ }^{1,3}$ \\ ${ }^{1}$ Mario Negri Institute for Pharmacological Research, Centro Anna Maria Astori, Science and Technology Park Kilometro \\ Rosso, Bergamo; ${ }^{2}$ Department of Pharmacological Sciences, Università di Milano, Milan; and ${ }^{3}$ Unit of Nephrology and \\ Dialysis, Azienda Ospedaliera, Ospedali Riuniti di Bergamo, Bergamo, Italy
}

Submitted 25 January 2010; accepted in final form 12 August 2010

\begin{abstract}
Zoja C, Corna D, Gagliardini E, Conti S, Arnaboldi L, Benigni A, Remuzzi G. Adding a statin to a combination of ACE inhibitor and ARB normalizes proteinuria in experimental diabetes, which translates into full renoprotection. Am J Physiol Renal Physiol 299: F1203-F1211, 2010. First published August 18, 2010; doi:10.1152/ajprenal.00045.2010.-The capacity of renin-angiotensin system (RAS) inhibitors to delay progression of diabetic nephropathy depends on the time at which therapy is started. A multimodal intervention is required to afford renoprotection in overt diabetic nephropathy. Here we assessed the effects of maximal RAS inhibition by angiotensin-converting enzyme (ACE) inhibitor plus angiotensin II type 1 receptor blocker (ARB) in combination with statin in rats with overt diabetic nephropathy. Uninephrectomized rats made diabetic by streptozotocin were orally treated from 4 (when proteinuria and renal lesions had developed) to 8 mo with vehicle, lisinopril plus candesartan, lisinopril plus candesartan plus rosuvastatin, or rosuvastatin alone. Systolic blood pressure increased in diabetic rats and was significantly lowered by combined therapies. Dual RAS blockade significantly reduced proteinuria compared with vehicle. Addition of statin further lowered proteinuria to control levels. Glomerulosclerosis was ameliorated by RAS inhibitors or statin, and regression was achieved by the addition of statin. Loss of podocytes of diabetic rats was limited by ACE inhibitor plus ARB while normalized by the three drugs. Defective nephrin expression of diabetes was increased by dual RAS blockade or statin and restored by the triple therapy. Tubular damage, interstitial inflammation, and expression of the fibrotic markers transforming growth factor (TGF)- $\beta 1$ and phosphorylated Smad $2 / 3$ in tubuli were significantly reduced by the triple regimen. These data suggest a strategy to target proteinuria to try to achieve regression of renal disease in diabetic patients who do not fully benefit from RAS inhibition alone.
\end{abstract}

dual renin-angiotensin system blockade; rosuvastatin; streptozotocininduced diabetes; glomerulosclerosis; tubular inflammation and fibrosis

DIABETES MELLITUS IS EMERGING as a global health care problem with devastating human, social, and economic impact, such that the total number of people with diabetes is projected to rise from 171 million in 2000 to 366 million in 2030 (54). About one-third of diabetic patients develop diabetic nephropathy, which accounts for $>40 \%$ of new cases of end-stage renal disease (38). Diabetic nephropathy is associated with a dramatic excess of cardiovascular morbidity, and cardiovascular mortality is the primary cause of early death in diabetic patients (30). In proteinuric chronic nephropathies, inhibitors of the renin-angiotensin system (RAS) are effective in reducing pro-

Address for reprint requests and other correspondence: C. Zoja, Mario Negri Institute for Pharmacological Research, Centro Anna Maria Astori, Science and Technology Park Km Rosso, Via Stezzano, 87, 24126 Bergamo, Italy (e-mail: carlamaria.zoja@marionegri.it). teinuria and slowing renal disease progression owing to their actions on systemic and glomerular hypertension as well as to their unique property of ameliorating size selectivity of the glomerular barrier, thereby limiting excess protein ultrafiltration and its deleterious consequences $(1,37)$. The capacity of RAS inhibitors to delay progression of diabetic nephropathy, however, crucially depends on the time at which therapy is started. Thus, in rats with streptozotocin-induced diabetes, early administration of angiotensin-converting enzyme (ACE) inhibitor significantly reduced systemic blood pressure and normalized urinary protein excretion. By contrast, a late intervention was unable to limit proteinuria despite an effective control of blood pressure (31). Results of clinical trials have shown that ACE inhibitors prevent the progression to overt nephropathy in the early microalbuminuric phase of diabetes $(24,33)$, whereas in a more advanced phase ACE inhibitors or angiotensin II type 1 receptor blockers (ARB) provide imperfect protection $(8,20,41)$. A more complex strategy than single pharmacological intervention in the RAS may therefore be required to afford renoprotection in diabetic patients with overt nephropathy. The combination of an ACE inhibitor and an ARB has been suggested as a way to maximize RAS blockade by affecting both the bioavailability and the activity of angiotensin II $(32,56)$. Metanalysis of randomized trials in patients with or without diabetes indicated that proteinuria reduction is greater when ACE inhibitor and ARB are used together (18), suggesting that a more efficient amelioration of the glomerular barrier can be obtained by the combined therapy (32), which might translate into increased renoprotection (42). Recently, the Ongoing Telmisartan Alone and in Combination with Ramipril Global Endpoint Trial (ONTARGET) (23) in patients with atherosclerotic vascular disease or diabetes with endorgan damage reported that although combination therapy reduced albuminuria to a greater extent than monotherapy, it worsened major renal outcomes. This study, however, had several weak points - as recently highlighted (43) - and the conclusions on dual RAS blockade are far from robust.

Statins or 3-hydroxy-3-methylglutaryl coenzyme A (HMG $\mathrm{CoA})$ reductase inhibitors have pleiotropic properties that complement their cholesterol-lowering effects. In addition to inhibiting the rate-limiting step in cholesterol biosynthesis, namely, the conversion of HMG CoA into mevalonate, statins interfere with prenylation of Ras and Rho family small GTP-binding proteins, thereby blocking the activation of signaling pathways and transcription factors, which regulate inflammatory and fibrogenic genes critical to renal disease progression (25).

A multimodal intervention strategy using all available tools to target urinary proteins has been envisioned as a rational 
approach to maximizing renoprotection in patients with chronic renal disease (44). Experimental data support this notion (57). Indeed, in rats with severe passive Heymann nephritis that only partially responded to ACE inhibitor therapy, the addition of statin to a chronic background of ACE inhibition and ARB induced remission of proteinuria and conferred complete protection of the kidney (57).

In the present study we wanted 1) to establish whether renoprotection can be better achieved by a multidrug approach with ACE inhibitor and ARB combined with statin than by dual RAS blockade in a setting of severe diabetic nephropathy and 2) to understand the mechanisms underlying the beneficial effects afforded by the triple therapy by looking at its impact in maintaining glomerular and tubulointerstitial structure and function.

\section{MATERIALS AND METHODS}

\section{Animals and Experimental Design}

Male Sprague-Dawley rats (Charles River Italia, Calco, Italy) with initial body weights of 270-330 g were used. Animal care and treatment were conducted in accordance with institutional guidelines that are in compliance with national (Decreto Legislativo n.116, Gazzetta Ufficiale suppl 40, 18 febbraio 1992, Circolare n.8, Gazzetta Ufficiale 14 luglio 1994) and international (EEC Council Directive 86/609, OJL358-1, December 1987; Guide for the Care and Use of Laboratory Animals, U.S. National Research Council, 1996) laws and policies. Animal protocols were submitted to and approved by the Institutional Animal Care and Use Committee (IACUC) of "Mario Negri" Institute, Milan, Italy. All animals were housed in a room in which the temperature was kept constant on a 12:12-h dark-light cycle and allowed free access to standard diet containing $20 \%$ protein by weight and tap water. Animals were subjected to right nephrectomy under anesthesia 7 days before the induction of diabetes in order to hasten the development of the disease (3). Diabetes was induced by a single intravenous injection of streptozotocin $(60 \mathrm{mg} / \mathrm{kg}$ body wt; Sigma, St. Louis, MO). The presence of diabetes was confirmed 2 days later by the measurement of the tail blood glucose level with a reflectance meter (A. Menarini Diagnostics, Florence, Italy). Diabetic rats received daily evening injections of insulin (Ultratard HM, Nordisk Farmaceutici, Rome, Italy) in doses individually adjusted to maintain a blood glucose level between 200 and $450 \mathrm{mg} / \mathrm{dl}$. Blood glucose levels were monitored at least twice a week in all diabetic rats and occasionally in control animals for comparison. At month 4 after diabetes induction (when proteinuria developed), rats were divided into four groups and treated until month 8 as follows: group $1(n=8)$, vehicle $(0.5 \%$ carboxymethylcellulose by gavage); group $2(n=6)$, lisinopril (12.5 mg/l in the drinking water) (3) plus candesartan (1 $\mathrm{mg} / \mathrm{kg}$ in $0.5 \%$ carboxymethylcellulose by gavage) (4); group $3(n=$ $8)$, lisinopril plus candesartan plus rosuvastatin $(5 \mathrm{mg} / \mathrm{kg}$ by gavage); group $4(n=6)$, rosuvastatin. Six normal animals given carboxymethylcellulose by gavage served as controls. An additional five diabetic rats together with four age-matched normal rats were killed at 4 mo after disease induction (before treatment) for renal histology analysis.

Systolic blood pressure (SBP) was recorded by the tail cuff method at baseline and at months 4 (before treatment) 6 , and 8 . Urinary excretion of proteins was measured in 24-h urine samples collected in metabolic cages at baseline and at different time intervals by the modified Coomassie blue $\mathrm{G}$ dye-binding assay for proteins with bovine serum albumin as standard. Urinary albumin excretion was determined before treatment started and at the end of the study by ELISA (Nephrat Exocell, Philadelphia, PA). Serum levels of creatinine, cholesterol, and triglycerides were measured by Reflotron test (Roche Diagnostic, Indianapolis, IN). Urinary creatinine was measured by ELISA (Nephrat Exocell). Creatinine clearance rate was calculated as urinary creatinine $\times$ urine volume/serum creatinine and expressed as milliliters per minute per $100 \mathrm{~g}$.

\section{Renal Histology}

The removed kidneys were fixed overnight in Duboscq-Brasil, dehydrated in alcohol, and embedded in paraffin. Kidney samples were sectioned at 3- $\mu \mathrm{m}$ intervals (Ultrotome V, LKB, Bromma, Sweden), and the sections were stained with Masson trichrome, hematoxylin and eosin, and periodic acid Schiff reagent (PAS stain). At least 100 glomeruli were examined for each animal, and the extent of glomerular damage was expressed as the percentage of glomeruli presenting sclerotic lesions. Tubular changes (atrophy, casts, and dilation) were graded from 0 to 4 ( 0 , no changes; 1 , changes affecting $<25 \%$ of the sample; 2 , changes affecting $25-50 \%$ of the sample; 3 , changes affecting $50-75 \%$ of the sample; 4 , changes affecting $75-100 \%$ of the sample). All renal biopsies were analyzed by the same pathologist, who was unaware of the nature of the experimental groups.

\section{Estimation of Glomerular Volume and Podocyte Count}

Glomerular volume was calculated with the use of a computer-based image analysis system (Image J 1.42q, http://rsb.info.nih.gov/ij) as previously described (22). Podocytes were identified with an antibody directed against Wilms tumor 1 (WT1), a podocyte-specific marker. The estimation of the average number of podocytes per glomerulus was determined in 30 glomeruli for each animal by morphometric analysis as proposed by Weibel (51) on digital images acquired by fluorescence microscopy (Olympus IX70) as previously reported (21).

\section{Immunohistochemical Analysis}

Indirect immunofluorescence was performed for the detection of interstitial macrophage infiltration (14) and adipophilin staining. Alkaline phosphatase-fast red technique was used to evaluate transforming growth factor (TGF)- $\beta 1$ expression (35). Immunoperoxidase method (2) was employed for nephrin and phosphorylated (p)Smad $2 / 3$ detection. The following primary antibodies were used: mouse anti-ED1 antigen present in rat monocytes/macrophages (1:100, Chemicon International, Temecula, CA), rabbit anti-TGF- $\beta 1$ (1:100, Santa Cruz Biotechnology, Santa Cruz, CA), goat anti-nephrin (1:100, Santa Cruz), goat anti-pSmad 2/3 (1:50, Santa Cruz), and mouse antiadipophilin (1:50, Progen Biotech, Heidelberg, Germany). ED1positive cells were counted in 15 randomly selected high-power microscopic fields $(\times 400)$ on average per animal. Adipophilin staining was evaluated in 13 randomly selected microscopic fields $(\times 200)$ on average per animal, and the percentage of area occupied by adipophilin-positive signal was quantified by setting a "threshold" with Image J's thresholding tool (1.42q, http://rsb.info.nih.gov/ij). Intensity of tubular TGF- $\beta 1$ and pSmad $2 / 3$ and glomerular nephrin signals were graded on a scale of 0 to 3 ( 0 , no staining; 1 , weak staining; 2, staining of moderate intensity; 3 , strong staining) in 20 randomly selected tubulointerstitial microscopic fields $(\times 200)$ or 30 glomeruli on average per animal. Negative controls were obtained by omitting the primary antibody on adjacent sections.

\section{Lipid Extraction and Free Cholesterol and Cholesteryl Ester Analysis}

Kidneys were thawed and homogenized with chloroform-methanol (2:1), BHT $0.01 \%$, and $\mathrm{KCl} 0.05 \%$ plus a known amount of stigmasterol and cholesteryl heptadecanoate (synthesized by Prof. Ermanno Valoti's laboratory, Università degli Studi di Milano, Milan, Italy) as internal standards. Two extractions were performed after 3-h shakings at $4{ }^{\circ} \mathrm{C}$ and the organic phase was dried under nitrogen and resuspended in chloroform-methanol $(2: 1)$ plus BHT. The aqueous phase was dried, and the resulting pellet was dissolved in $0.1 \mathrm{~N} \mathrm{NaOH}$. Total protein amount was measured and results are expressed as micrograms of lipid per milligram of protein (40). 
An aliquot of the lipid extract was loaded onto prerun and activated channeled Silica TLC plates (BioMap) in hexane-diethyl ether-acetic acid (80:20:1 vol/vol/vol). After the run, the plates were sprayed with dichlorofluorescein $(0.15 \%$ in ethanol) and the spots corresponding to those of known standards of free and esterified cholesterol were scraped off. Free cholesterol was extracted from silica with hexaneisopropanol and detected without derivatization. Cholesteryl esters were derivatized with methanol-HCl $3 \mathrm{~N}$-toluene for $2 \mathrm{~h}$ at $75^{\circ} \mathrm{C}$. The analysis was performed on a DANI 1000 gas liquid chromatographer (GLC) (DANI Instruments, Milan, Italy) equipped with a flame ionization detector and a 30-m, 0.32-mm, 0.25- $\mu \mathrm{m}$ MEGA-1 (Mega Columns, Legnano, Italy) fused silica column. The flow of hydrogen was at a constant pressure of $1 \mathrm{bar}$, and the detector temperature was $300^{\circ} \mathrm{C}$. Oven temperature ranged for free cholesterol from 185 to $300^{\circ} \mathrm{C}$ (total run $15 \mathrm{~min}$ ) and for cholesteryl esters from 160 to $300^{\circ} \mathrm{C}$ (total run $28 \mathrm{~min}$ ). Chromatograms were recorded and the area of each peak quantified by Clarity Software (Clarity, Prague, Czech Republic). The mass of free cholesterol was calculated by comparing its area with that of the internal standard (stigmasterol), while the mass of cholesteryl esters was evaluated after integrating and summing the areas of each fatty acid composing the ester and comparing the total area with that of the internal standard (cholesteryl heptadecanoate) (49).

\section{Statistical Analysis}

Results are expressed as means \pm SE. Data were analyzed by ANOVA with the Bonferroni post hoc analysis for multiple comparison or nonparametric Kruskal-Wallis test. The statistical significance level was defined as $P<0.05$.

\section{RESULTS}

\section{Systemic Parameter}

By the end of the study one rat died in each group of diabetic rats. All control rats were alive. Diabetic rats gained weight with time, although to a lesser extent than control rats (Table 1). At the end of the study, mean body weights of rats given a combination of lisinopril and candesartan or lisinopril plus candesartan plus rosuvastatin were significantly lower $(P<$ $0.05)$ than those of diabetic rats treated with vehicle or statin alone. Food intake was comparable among diabetic rats and significantly higher than that of control rats (Table 1).

As shown in Table 1, serum cholesterol levels were comparable among the groups of diabetic and control rats. Serum triglyceride levels were significantly increased in diabetic rats given vehicle compared with control rats. Hypertriglyceridemia was reduced in all diabetic treated rats, as a likely consequence of the antiproteinuric effect of the therapy, although statistical significance was not achieved.

Rats with diabetes showed over time a significant increase in SBP compared with control rats (Fig. 1). Treatment with ACE inhibitor plus ARB, or with the addition of rosuvastatin,

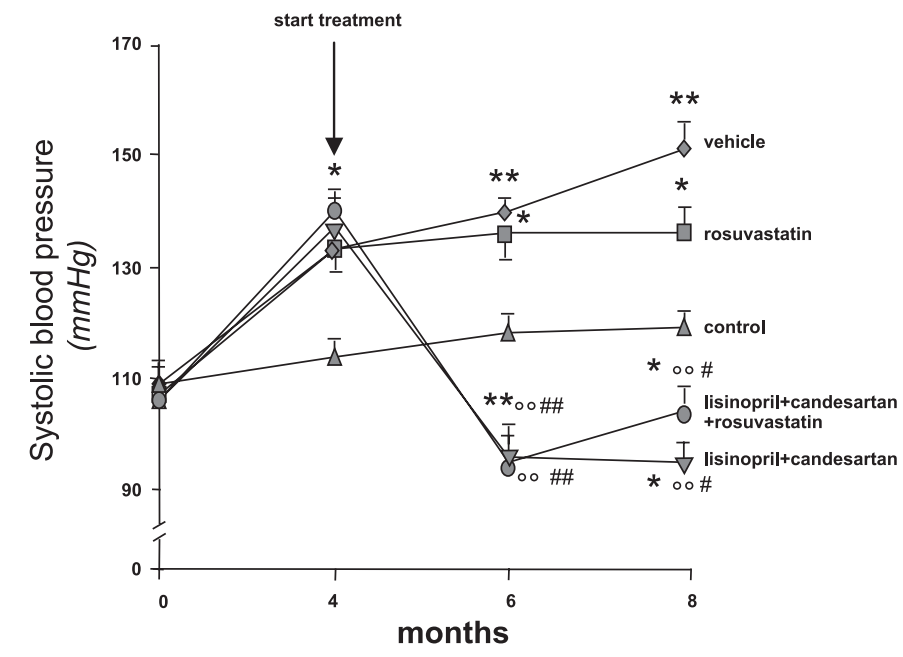

Fig. 1. Time course of systolic blood pressure in control and diabetic rats treated with vehicle, lisinopril + candesartan, lisinopril + candesartan + rosuvastatin, or rosuvastatin, from 4 to 8 mo. Data are means \pm SE. $* P<0.05$, $* * P<0.01$ vs. control; ${ }^{\circ} P<0.01$ vs. vehicle; $\# P<0.05, \# \# P<0.01$ vs. rosuvastatin at corresponding time.

maintained SBP at values significantly lower than those of the vehicle group and even of age-matched control rats. In rats given rosuvastatin alone, SBP values were numerically lower than those measured in vehicle-treated rats, which is in line with the antihypertensive effects reported for statins $(13,27)$ and attributed to drug interaction with endothelial function or angiotensin II receptors (7).

\section{Renal Parameters}

The time course of urinary protein excretion is shown in Fig. $2 A$. At $4 \mathrm{mo}$, rats with diabetes exhibited significantly higher values of urinary protein excretion than control rats and were randomized to receive treatments. Proteinuria progressively increased in rats given vehicle, averaging $94 \pm 24 \mathrm{mg} /$ day at 8 mo. Combined administration of lisinopril and candesartan reduced proteinuria compared with pretreatment, and levels were significantly $(P<0.05)$ lower than those measured in vehicle-treated rats (month $8,38 \pm 12 \mathrm{mg} /$ day). Remarkably, when rosuvastatin was added on top of dual RAS blockade, proteinuria was further lowered and normalized (month 8 , $24 \pm 2 \mathrm{mg} /$ day; $P<0.01$ vs. vehicle) to the levels of control rats (month $8,25 \pm 3 \mathrm{mg} /$ day). In diabetic rats treated with rosuvastatin the mean proteinuria levels were numerically lower than those measured in rats receiving vehicle (month 8 , $78 \pm 20 \mathrm{mg} /$ day). A similar trend was observed for urinary albumin excretion (Fig. 2B).

Table 1. Systemic parameters measured in diabetic rats at 8 mo after disease induction

\begin{tabular}{|c|c|c|c|c|c|}
\hline Groups & Body Wt, g & $\begin{array}{l}\text { Food Intake, } \\
\mathrm{g} / 24 \mathrm{~h}\end{array}$ & $\begin{array}{l}\text { Serum Cholesterol, } \\
\mathrm{mg} / \mathrm{dl}\end{array}$ & $\begin{array}{c}\text { Serum Triglycerides, } \\
\text { mg/dl }\end{array}$ & $\begin{array}{c}\text { Creatinine Clearance, } \\
\mathrm{ml} \cdot \mathrm{min}^{-1} \cdot 100 \mathrm{~g}^{-1}\end{array}$ \\
\hline \multicolumn{6}{|l|}{ Diabetes } \\
\hline Vehicle & $472 \pm 15 \dagger$ & $41 \pm 2 \dagger$ & $110 \pm 9$ & $195 \pm 30^{*}$ & $0.26 \pm 0.03$ \\
\hline Lisinopril + candesartan & $422 \pm 6 \dagger+\S$ & $43 \pm 3^{*}$ & $102 \pm 2$ & $126 \pm 18$ & $0.30 \pm 0.02$ \\
\hline Lisinopril + candesartan + rosuvastatin & $417 \pm 14 \dagger+$ & $40 \pm 4^{*}$ & $106 \pm 3$ & $124 \pm 15$ & $0.27 \pm 0.02$ \\
\hline Rosuvastatin & $483 \pm 32^{*}$ & $39 \pm 3^{*}$ & $102 \pm 2$ & $147 \pm 15$ & $0.25 \pm 0.01$ \\
\hline Control & $607 \pm 21$ & $24 \pm 2$ & $100 \pm 0$ & $112 \pm 8$ & $0.29 \pm 0.01$ \\
\hline
\end{tabular}

Values are expressed as means \pm SE. $* P<0.05, \dagger P<0.01$ vs. control rats; $\ddagger P<0.05$ vs. vehicle; $\S P<0.05$ vs. rosuvastatin. 
A

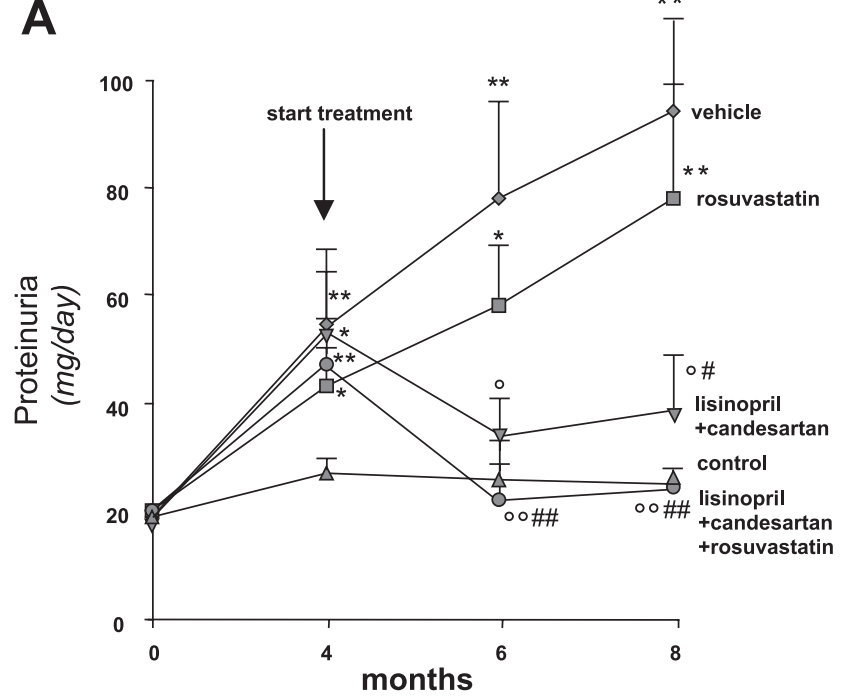

B

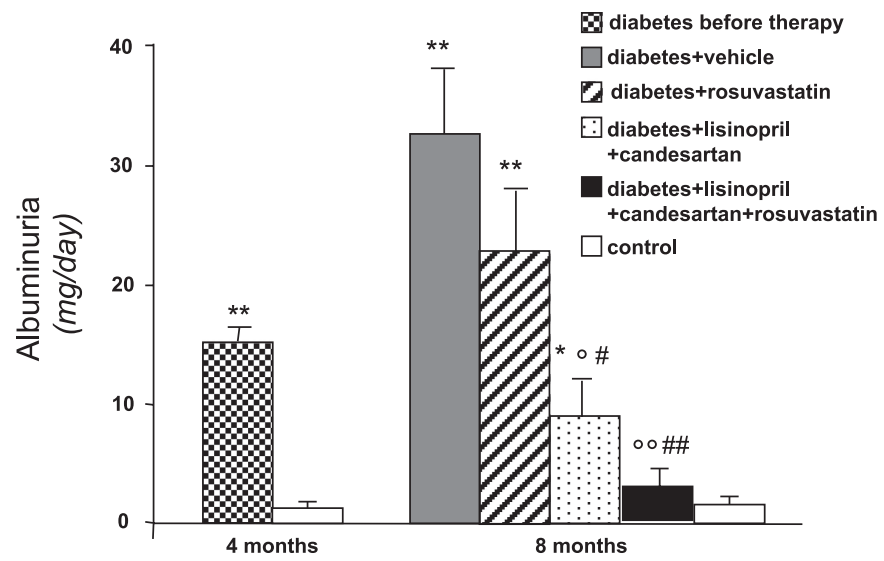

Fig. 2. A: time course of urinary protein excretion in control and diabetic rats treated with vehicle, lisinopril + candesartan, lisinopril + candesartan + rosuvastatin, or rosuvastatin from 4 to $8 \mathrm{mo}$. $B$ : urinary albumin levels at $4 \mathrm{mo}$ (before treatment) and 8 mo. Data are means \pm SE. $* P<0.05, * * P<0.01$ vs. control; ${ }^{\circ} P<0.05,{ }^{\circ} P<0.01$ vs. vehicle; $\# P<0.05$, \#\#P<0.01 vs. rosuvastatin at corresponding time.

Renal function, as evaluated by creatinine clearance at month 8 , was mildly impaired in diabetic rats given vehicle compared with control rats (Table 1). Treatments did not significantly affect renal function.

\section{Glomerular Pathology}

Histology. Morphological evaluation of the kidney in diabetic rats at 4 mo revealed the presence of $2 \pm 0.01 \%$ sclerotic glomeruli on average $(P<0.05$ vs. age-matched control rats: $0.08 \pm 0.002 \%$ ) (Fig. 3). At 8 mo diabetic rats given vehicle showed variable degrees of glomerulosclerosis and hyalinosis with segmental collapse of the glomerular tuft affecting $10.6 \pm$ $1.8 \%$ of glomeruli on average $(P<0.01$ vs. diabetes at $4 \mathrm{mo}$; $P<0.01$ vs. age-matched control rats: $2.2 \pm 0.4 \%$ ). Administration of lisinopril plus candesartan decreased the incidence of glomerulosclerosis $(4.9 \pm 1.6 \%)$, but not to a significant extent. A complete protection was instead conferred by the addition of rosuvastatin to the RAS inhibitors, so that the percentage of glomeruli with sclerotic changes $(1.2 \pm 0.3 \%)$ was lower than that observed in diabetic animals at $4 \mathrm{mo}$, thereby suggesting regression of glomerular lesions. Rosuvastatin treatment limited the degree of glomerulosclerosis (5.7 \pm $1.6 \%$ ), but without reaching a statistical significance compared with vehicle.

Morphometric analysis: glomerular volume, podocyte number, and nephrin expression. Glomerular hypertrophy was observed in diabetic rats receiving vehicle (Fig. 4A). Treatments with lisinopril plus candesartan or rosuvastatin alone numerically reduced the glomerular volume. A significant reduction $(P<0.05)$ of glomerular hypertrophy was achieved after the triple therapy. The number of podocytes per glomerulus was significantly decreased in diabetic rats given vehicle compared with control rats $(P<0.05)$. Loss of podocytes per glomerulus was limited by dual RAS blockade. Treatment with the triple therapy restored the number of podocytes to control values (Fig. $4 A$ ). Only a partial effect on podocyte number was observed after treatment with rosuvastatin alone. An intense expression of nephrin protein with the typical epithelial-like staining pattern was detected in glomeruli of control rats (score: $2.70 \pm 0.08$, Fig. $4 \mathrm{Be}$ ). Diabetic rats given vehicle showed a significant $(P<0.01)$ reduction in nephrin expression (score: $1.49 \pm 0.19$, Fig. $4 B a$ ) compared with control rats. Nephrin staining was markedly increased after the administration of either lisinopril plus candesartan (score: $2.23 \pm 0.13$, $P<0.05$ vs. vehicle; Fig. $4 B c$ ) or rosuvastatin alone (score: $2.22 \pm 0.22, P<0.05$ vs. vehicle; Fig. $4 B b$ ). Notably, in diabetic animals receiving the triple therapy nephrin expression was restored, so that levels were similar to those of control animals (score: $2.68 \pm 0.06, P<0.01$ vs. vehicle; Fig. $4 B d$ ).

\section{Tubulointerstitial Pathology}

Histology. In diabetic rats glomerular injury was associated with mild tubular damage (Fig. 5A), which increased with time from 4 mo (score: $0.60 \pm 0.24$ ) to 8 mo (score: $1.01 \pm 0.03$, $P<0.01$ vs. controls: $0.16 \pm 0.12$ ). Tubular lesions were significantly reduced by combined treatment of lisinopril and candesartan (score: $0.25 \pm 0.25, P<0.05$ vs. vehicle) and normalized by the triple therapy (score: $0.13 \pm 0.13, P<0.01$

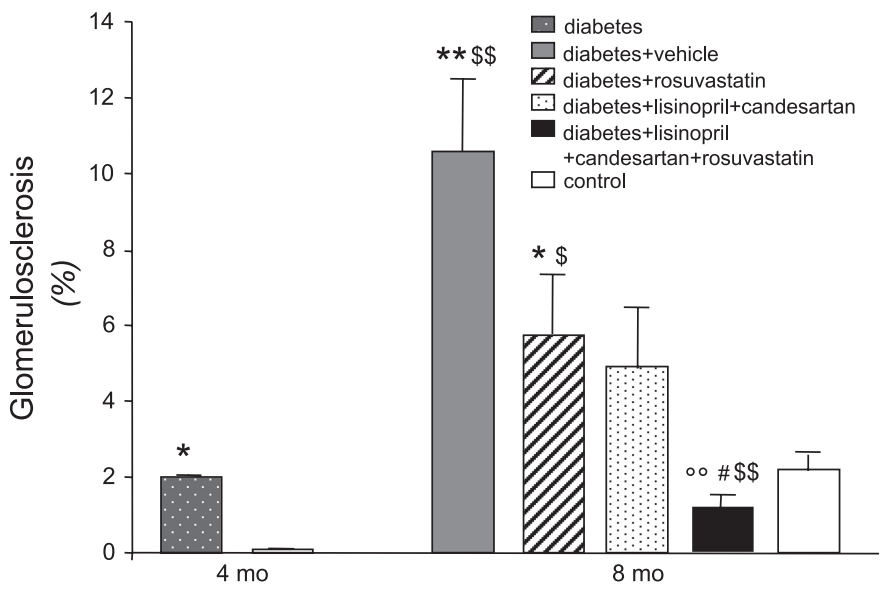

Fig. 3. Incidence of glomerulosclerosis in diabetic animals at 4 mo (before treatment) and 8 mo after administration of vehicle, rosuvastatin, lisinopril + candesartan, or lisinopril + candesartan + rosuvastatin and in control rats. Values are expressed as means \pm SE. $* P<0.05, * * P<0.01$ vs. control at corresponding time; $\$ P<0.05, \$ \$ P<0.01$ vs. vehicle at $4 \mathrm{mo} ;{ }^{\circ} P<0.01$ vs. vehicle at $8 \mathrm{mo} ; \# P<0.01$ vs. rosuvastatin. 
A

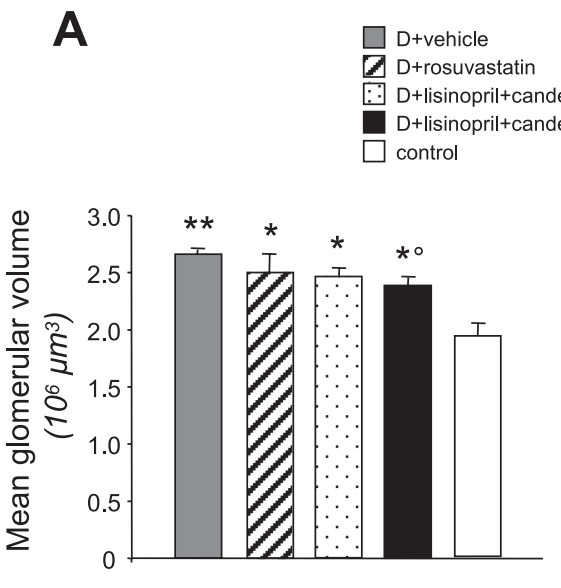

B
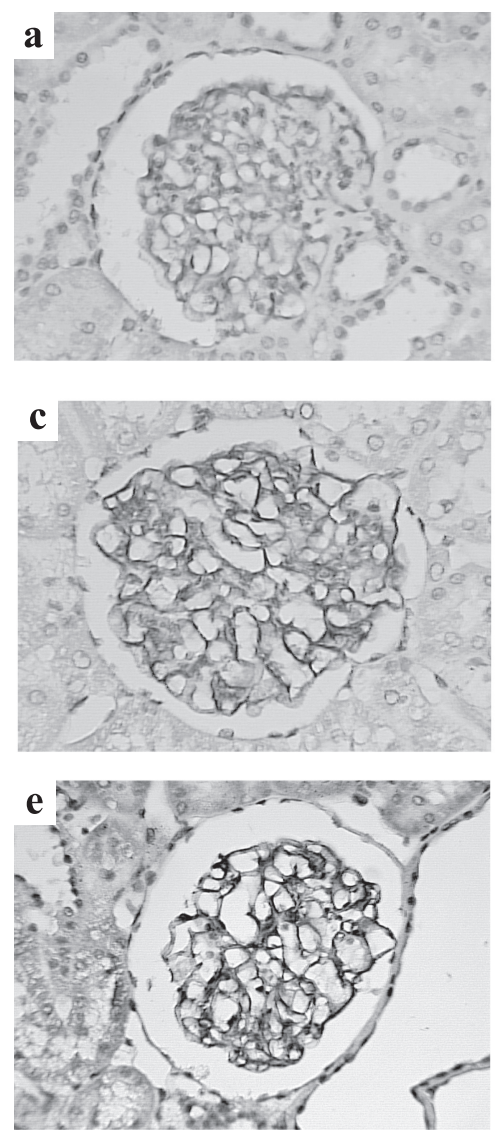
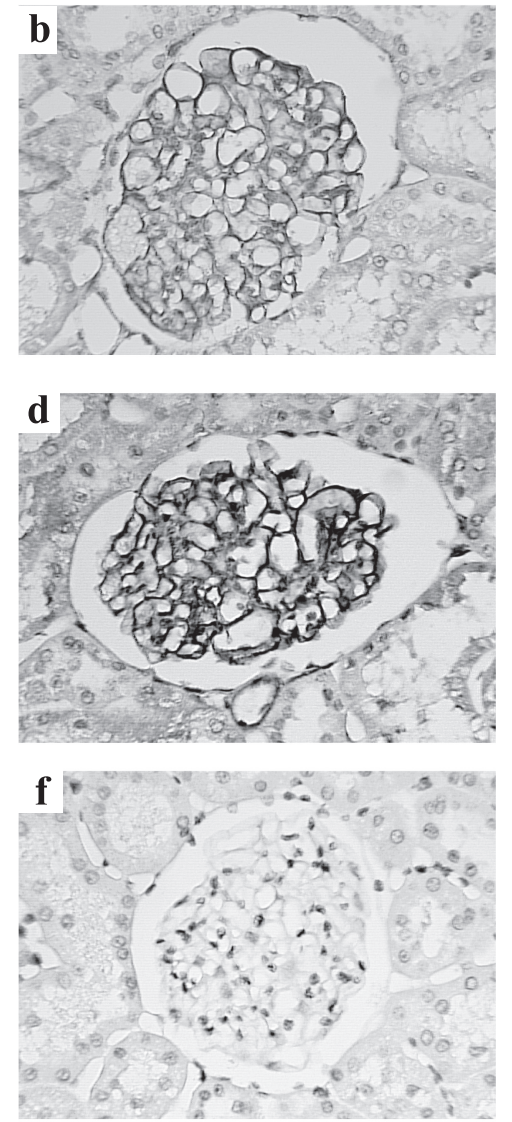

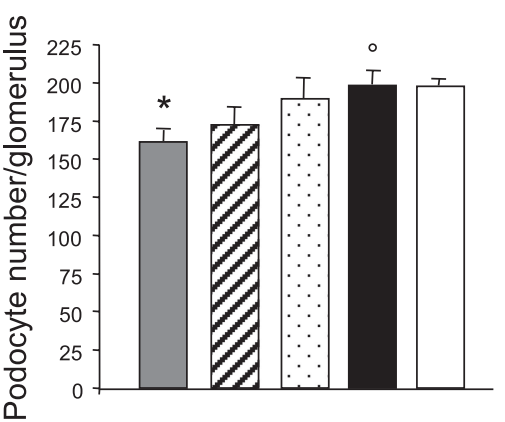

Fig. 4. A: morphometric estimation of mean glomerular volume and average number of podocytes per glomerulus in diabetic rats (D) receiving vehicle, rosuvastatin, lisinopril + candesartan, or lisinopril + candesartan + rosuvastatin and in control rats. Values are expressed as means \pm SE. ${ }^{*} P<0.05, * * P<0.01$ vs. control; ${ }^{\circ} P<0.05$ vs. vehicle. $B$ : representative photomicrographs of nephrin expression by immunoperoxidase in diabetic animals receiving vehicle $(a)$, rosuvastatin $(b)$, lisinopril + candesar$\tan (c)$, or lisinopril + candesartan + rosuvastatin $(d)$ and in control rats $(e)$. Staining was completely abrogated by omitting the primary antibody on the adjacent section on each slide, indicating staining specificity $(f)$. Original magnification $\times 600$ vs. vehicle). In diabetic rats given rosuvastatin the score of tubular damage averaged $0.60 \pm 0.24$.

Interstitial inflammation and fibrosis. Accumulation of ED1positive monocytes/macrophages was found in peritubular cortical interstitium of diabetic rats given vehicle (Fig. 5B). Treatment with lisinopril plus candesartan numerically reduced the interstitial accumulation of inflammatory cells compared with vehicle. A further significant reduction was observed after the triple therapy. Rosuvastatin alone limited inflammatory cell infiltrates to an extent similar to the combined treatment of ACE inhibitor and ARB. Tubular lesions and interstitial inflammation observed in diabetic animals given vehicle were accompanied by increased tubular expression of the profibrotic marker TGF- $\beta 1$ (Fig. 6). TGF- $\beta 1$ staining was decreased after ACE inhibitor plus ARB treatment (Fig. 6C) compared with vehicle-treated rats (Fig. 6A). A further reduction was observed after the triple regimen (Fig. $6 D$ ), to the extent that TGF- $\beta 1$ expression was fairly comparable to that found in control rats (Fig. 6E). A 24\% reduction in tubular TGF- $\beta 1$ expression compared with vehicle was observed after treatment with rosuvastatin alone (Fig. 6B). Upregulation of tubular TGF- $\beta 1$ in diabetic rats given vehicle was associated with activation of the intracellular cascade of Smad proteins, particularly pSmad $2 / 3$ (6), which are specifically involved in the regulation of 

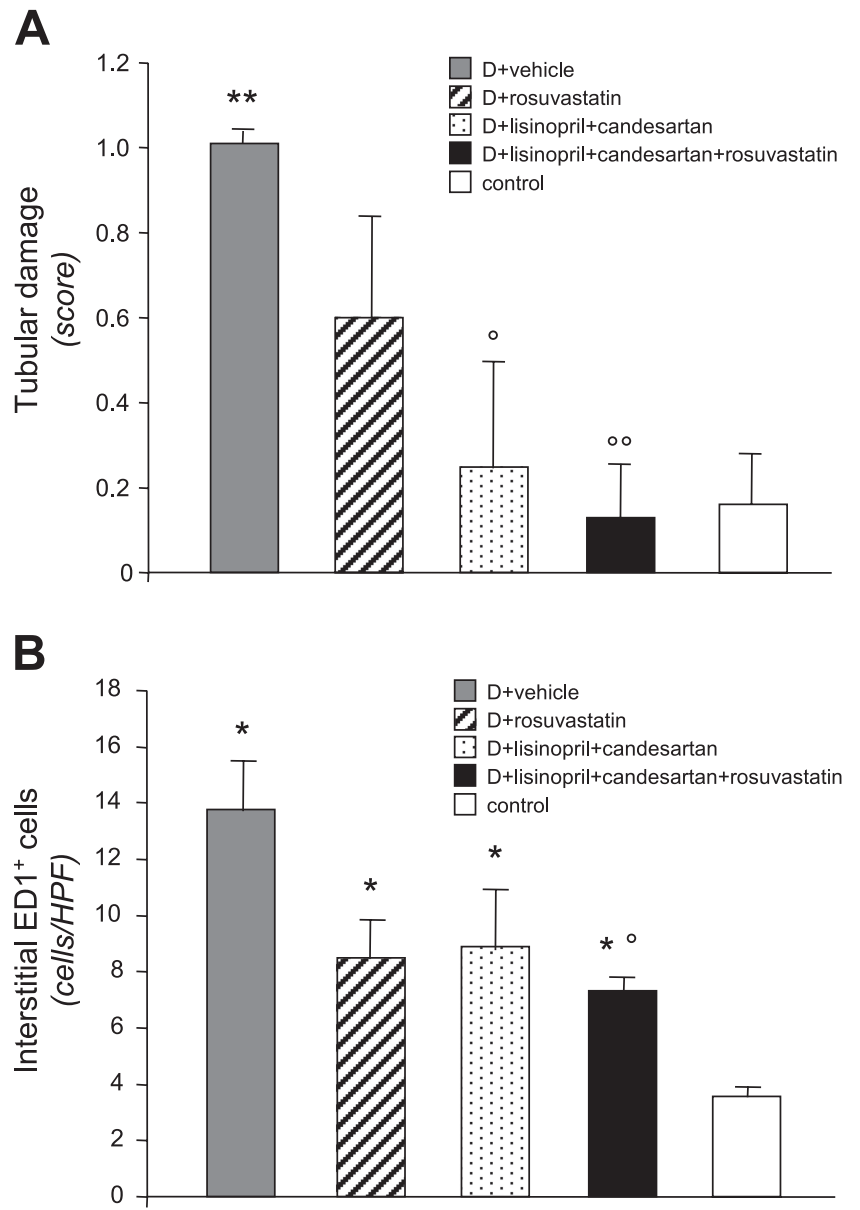

Fig. 5. Tubular damage $(A)$ and interstitial accumulation of ED1-positive monocytes/macrophages $(B)$ in diabetic rats after administration of vehicle, rosuvastatin, lisinopril + candesartan, or lisinopril + candesartan + rosuvastatin and in control rats. Values are expressed as means \pm SE. $* P<0.05$, $* * P<0.01$ vs. control; ${ }^{\circ} P<0.05,{ }^{\circ} P<0.01$ vs. vehicle. HPF, high-power field.

TGF- $\beta$-dependent fibrogenic responses (Fig. 7). The increased pSmad 2/3 staining in tubuli of diabetic rats on vehicle (Fig. $7 A$ ) was partially, but not significantly, reduced by lisinopril plus candesartan (Fig. 7C). A statistically significant difference was achieved after the addition of rosuvastatin to the dual therapy (Fig. 7D). Rosuvastatin alone (Fig. 7B) limited tubular pSmad $2 / 3$ expression to an extent similar to that of the dual therapy.

\section{Renal Lipid Accumulation}

Lipid analysis revealed a numerically increased free and esterified cholesterol content in the kidneys of diabetic rats receiving vehicle (Table 2). A trend toward a decrease in cholesterol was observed in the kidneys of rats treated with rosuvastatin, alone or in association with the other regimens, although statistical significance was not reached. Treatment with lisinopril plus candesartan showed only a modest effect in reducing lipid accumulation, confined to the esterified form of cholesterol (Table 2).

The immunolocalization of adipocyte differentiation-related protein adipophilin, a marker of cytoplasmic lipid droplets (16), revealed almost no lipid droplets in control rats and a significant increase of the typical lipid droplets as ring-shaped red dots in the tubules of diabetic rats on vehicle (Table 2). The accumulation of lipid droplets was significantly reduced by combined treatment with lisinopril and candesartan and by the triple therapy. Rosuvastatin alone also reduced tubular adipophilin expression to a significant extent (Table 2).

\section{DISCUSSION}

Results from the present study demonstrate that in rats with overt diabetic nephropathy that benefited only partially from ACE inhibitor treatment $(3,14)$, the addition of candesartan to
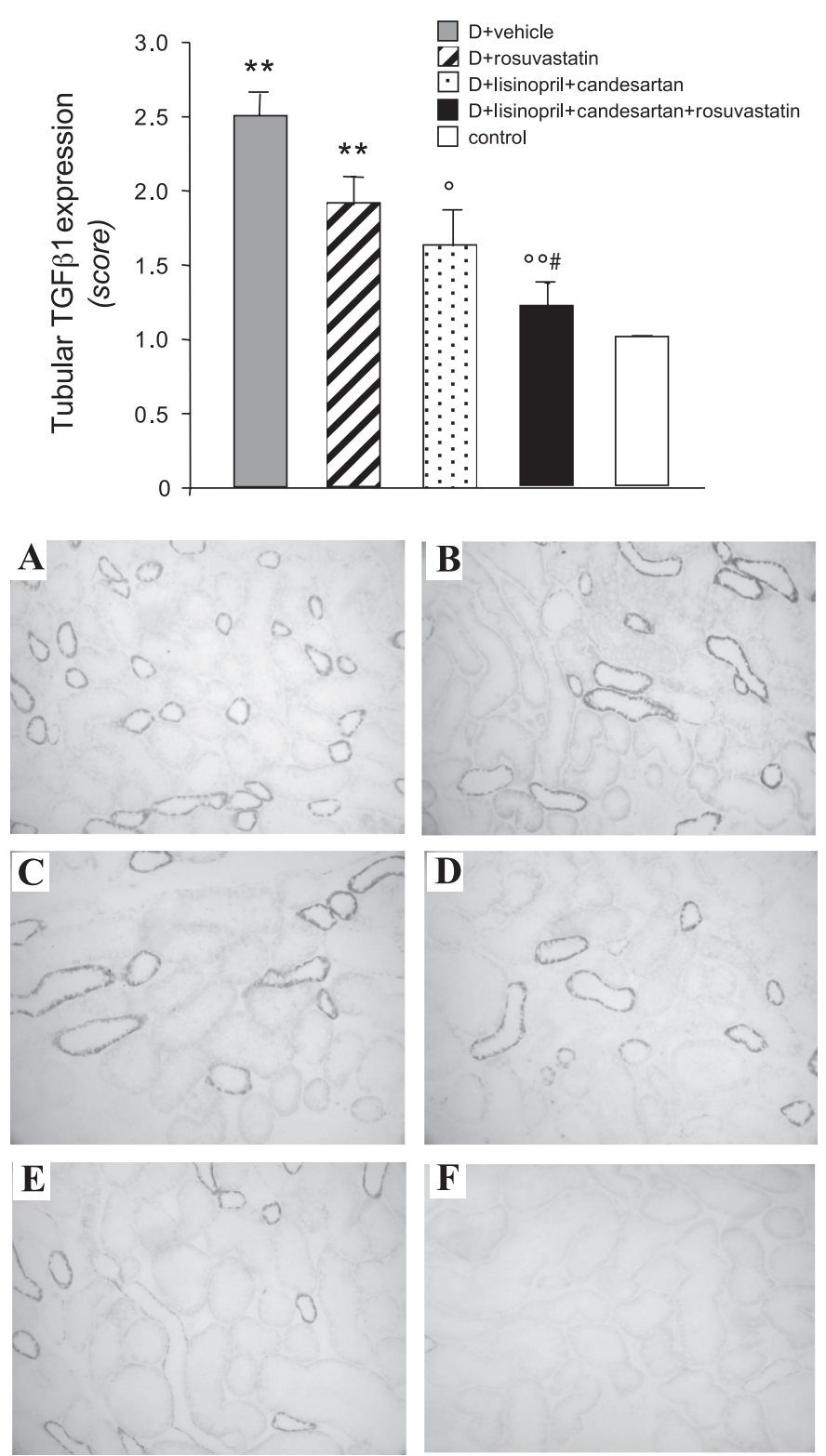

Fig. 6. Scores (top) and representative photomicrographs (bottom) of tubular transforming growth factor (TGF)- $\beta 1$ expression in diabetic rats receiving vehicle $(A)$, rosuvastatin $(B)$, lisinopril + candesartan $(C)$, or lisinopril + candesartan + rosuvastatin $(D)$ and in control rats $(E)$. Staining was completely abrogated by omitting the primary antibody on the adjacent section on each slide, indicating staining specificity $(F)$. Original magnification $\times 200$. Score values are expressed as means $\pm \mathrm{SE}$. $* * P<0.01$ vs. control; ${ }^{\circ} P<0.05$, ${ }^{\circ} P<0.01$ vs. vehicle; $\# P<0.05$ vs. rosuvastatin. 

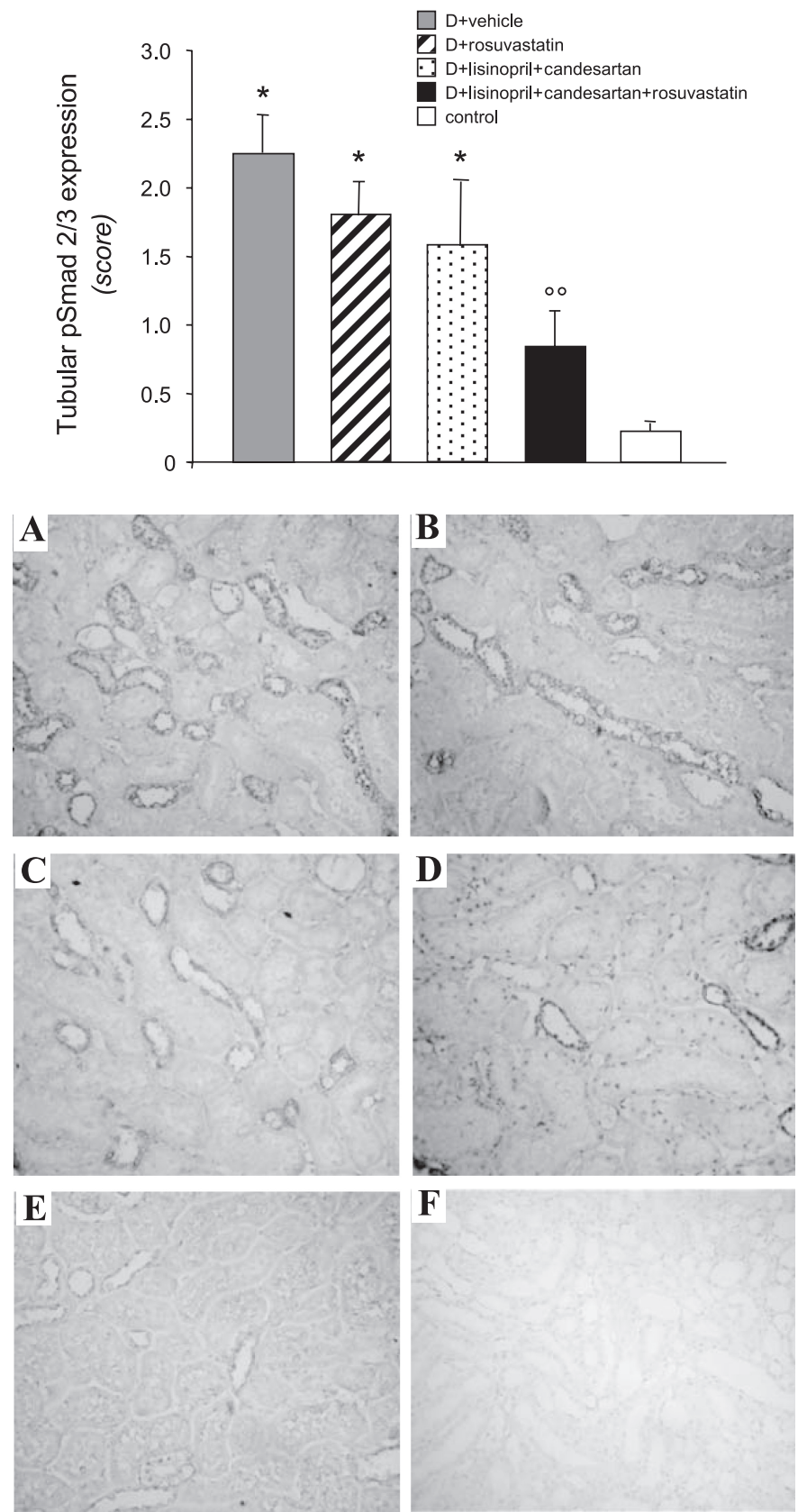

Fig. 7. Scores (top) and representative photomicrographs (bottom) of tubular phosphorylated (p)Smad 2/3 expression in diabetic rats given vehicle $(A)$, rosuvastatin $(B)$, lisinopril + candesartan $(C)$, or lisinopril + candesartan + rosuvastatin $(D)$ and in control rats $(E)$. Staining was completely abrogated by omitting the primary antibody on the adjacent section on each slide, indicating staining specificity $(F)$. Original magnification $\times 200$. Score values are expressed as means \pm SE. $* P<0.05$ vs. control; ${ }^{\circ} P<0.01$ vs. vehicle.

lisinopril reduced proteinuria to a significant extent compared with diabetic rats receiving vehicle and markedly, albeit not significantly, ameliorated the degree of glomerulosclerosis. When rosuvastatin was added on top of ACE inhibition and angiotensin II type 1 receptor blockade, proteinuria was lowered to levels of control rats, indicating restoration of the glomerular barrier function, and full protection of the kidney was obtained. The mechanism(s) underlying the strong antiproteinuric effect afforded by the triple therapy in diabetic rats could be related to the combined drugs' action on glomerular filtration barrier function. Abnormalities in size-selective function of the glomerular capillary wall have been consistently shown by dextran or Ficoll fractional clearance studies in experimental and human diabetes, with increase in the number of large nonselective pores responsible for the passage of circulating macromolecules in the urinary space $(14,29,36$, $39,41)$. Both ACE inhibitors and ARB reduced pore dimensions and improved size selectivity of the glomerular membrane in rats with streptozotocin-induced diabetes $(14,36)$ and in patients with type 1 diabetes (29) which translated into a reduction of proteinuria. That statins may ameliorate diabetesinduced changes in glomerular permeability has been suggested by recent data showing that treatment with rosuvastatin resulted in near-normalization of the abnormal glomerular filtration of 70- and 40-kDa dextrans in streptozotocin-diabetic rats (28). The favorable effects of rosuvastatin on glomerular permeability were possibly related to statin's ability to inhibit the activation of Rho signaling pathways shown to decrease endothelial barrier function (10).

Podocytes span the glomerular capillaries and function via the slit diaphragm as a critical barrier to macromolecule filtration (46). Studies have highlighted that reduction in podocyte number is an early feature of diabetic nephropathy that predicts long-term urinary albumin excretion and progressive course of the disease $(12,26,53)$. Reduced podocyte number can reflect increased podocyte detachment and/or apoptosis $(48,55)$. As a consequence of podocyte depletion, the remaining podocytes are induced to cover the denuded basement membrane, whereas the mesangial compartment expands to further compensate for the ongoing cell loss (46), which would favor glomerular hypertrophy in diabetes. In the present study we confirmed a reduced podocyte number per glomerulus in diabetic rats given vehicle, which was associated with increased glomerular volume and the development of glomerulosclerosis. The dual blockade of RAS with lisinopril and candesartan markedly limited podocyte loss, but only triple therapy resulted in a complete preservation of podocyte number and a reduction of glomerular volume. That RAS inhibitors can influence podocyte loss has been previously documented in diabetic rats $(14,15)$. An interesting finding here is that the administration of rosuvastatin alone partially limited podocyte loss of diabetic rats. Among possible mechanisms, recent in vitro data have shown that rosuvastatin protected injured podocytes from undergoing apoptosis through upregulation of the cell cycle

Table 2. Free and esterified cholesterol levels and adipophilin expression in kidney tissue of diabetic rats at 8 mo after disease induction

\begin{tabular}{lccc}
\hline \hline \multicolumn{1}{c}{ Groups } & $\begin{array}{c}\text { Free } \\
\text { Cholesterol, } \\
\mu \mathrm{g} / \mathrm{mg} \text { protein }\end{array}$ & $\begin{array}{c}\text { Esterified } \\
\text { Cholesterol, } \\
\mu \mathrm{g} / \mathrm{mg} \text { protein }\end{array}$ & $\begin{array}{c}\text { Adipophilin } \\
\text { Expression, \% }\end{array}$ \\
\hline $\begin{array}{l}\text { Diabetes } \\
\text { Vehicle }\end{array}$ & $65.04 \pm 2.42$ & $4.20 \pm 0.53$ & $1.80 \pm 0.1^{*}$ \\
$\quad \begin{array}{l}\text { Lisinopril + candesartan } \\
\text { Lisinopril + candesartan }+ \\
\quad \text { rosuvastatin }\end{array}$ & $56.20 \pm 3.53$ & $3.36 \pm 0.23$ & $0.50 \pm 0.3 \dagger$ \\
$\quad \begin{array}{l}\text { Rosuvastatin } \\
\text { Control }\end{array}$ & $58.18 \pm 2.39$ & $3.24 \pm 0.12$ & $0.72 \pm 0.3 \dagger$ \\
\hline & $62.31 \pm 4.90$ & $3.40 \pm 0.82$ & $0.27 \pm 0.5$ \\
\hline
\end{tabular}

Values are expressed as means \pm SE. $* P<0.01$ vs. control rats; $\dagger P<0.01$ vs. vehicle. 
regulator p21, a prosurvival player in podocyte apoptosis (11). There is also evidence showing that statins may directly stimulate Akt-dependent survival pathway in podocytes. Thus treatment with statins reduced oxidized LDL-induced apoptosis in cultured human podocytes by activating Akt/phosphatidylinositol 3-kinase signaling pathway (9). In the same study, it was shown that the statin-induced Akt activation also protected podocytes from the loss of nephrin, the slit diaphragm protein that acts to maintain slit pore integrity and renal filtration capacity (50), which would provide a mechanism for the antiproteinuric effect of statins. In the present study, the defective nephrin protein levels found in the glomeruli of diabetic rats receiving vehicle were improved by rosuvastatin to an extent similar to that of dual RAS blockade. While improvement in nephrin expression after ACE inhibitor treatment has been previously documented in both experimental (5, $14,17)$ and human (19) diabetic nephropathy, few reports are available showing the ability of statins to ameliorate decreased expression of nephrin, and they refer to models of proteinuric renal disease other than diabetic nephropathy $(47,52)$. Remarkably, when rosuvastatin was added to lisinopril and candesartan, we obtained restoration of nephrin expression, which paralleled the regression of proteinuria to normal values.

In the present study, we unequivocally showed that normalization of proteinuria by the triple therapy translated into preservation of the tubular structure, reduction of interstitial inflammation, and almost complete abrogation of the abnormal tubular expression of TGF- $\beta 1$, a central player in the fibrogenic process of diabetic nephropathy $(34,45)$. Moreover, the finding of reduced staining for $\mathrm{pSmad} 2 / 3$ in the tubuli of rats treated with ACE inhibitor plus ARB plus statin further indicated the antifibrotic effects of the triple regimen. It has been reported that in the profibrotic process TGF- $\beta$ signaling involves TGF- $\beta$ receptor-activated Smad 2 and 3, which, once phosphorylated, bind to Smad 4. The resulting Smad complex translocates into the nucleus, where it cooperates with numerous transcription factors to regulate the transcription of profibrogenic genes (6).

In conclusion, these data indicate that adding a statin to a background of ACE inhibition and angiotensin II receptor blockade therapy normalizes proteinuria and affords better renoprotection than a dual RAS blockade in rats with overt diabetic nephropathy. These results reinforce the concept that targeting proteinuria is the best way to induce regression of renal disease, and suggest this multidrug approach as a strategy for both proteinuric diabetic and nondiabetic patients who do not fully benefit from ACE inhibitor and ARB treatment.

\section{ACKNOWLEDGMENTS}

The authors thank Giovanna Barcella and Romana Stacchetti for their precious help in animal care and Monica Locatelli for excellent technical assistance. Manuela Passera helped to prepare the manuscript.

\section{GRANTS}

The present study was supported in part by a grant from AstraZeneca Italia, Milan, Italy. S. Conti was the recipient of a fellowship from Fondazione Aiuti per la Ricerca sulle Malattie Rare (ARMR) in memory of Lidia D'Arcangelo, Bergamo, Italy.

\section{DISCLOSURES}

No conflicts of interest, financial or otherwise, are declared by the authors.

\section{REFERENCES}

1. Abbate M, Zoja C, Remuzzi G. How does proteinuria cause progressive renal damage? J Am Soc Nephrol 17: 2974-2984, 2006.

2. Benigni A, Tomasoni S, Gagliardini E, Zoja C, Grunkemeyer JA, Kalluri R, Remuzzi G. Blocking angiotensin II synthesis/activity preserves glomerular nephrin in rats with severe nephrosis. J Am Soc Nephrol 12: 941-948, 2001.

3. Benigni A, Zoja C, Corna D, Zatelli C, Conti S, Campana M, Gagliardini E, Rottoli D, Zanchi C, Abbate M, Ledbetter S, Remuzzi G. Add-on anti-TGF- $\beta$ antibody to ACE inhibitor arrests progressive diabetic nephropathy in the rat. J Am Soc Nephrol 14: 1816-1824, 2003.

4. Benigni A, Zoja C, Tomasoni S, Campana M, Corna D, Zanchi C, Gagliardini E, Garofano E, Rottoli D, Ito T, Remuzzi G. Transcriptional regulation of nephrin gene by peroxisome proliferator-activated receptor-gamma agonist: molecular mechanism of the antiproteinuric effect of pioglitazone. J Am Soc Nephrol 17: 1624-1632, 2006.

5. Blanco S, Bonet J, Lopez D, Casas I, Romero R. ACE inhibitors improve nephrin expression in Zucker rats with glomerulosclerosis. Kidney Int Suppl: S10-S14, 2005.

6. Blobe GC, Schiemann WP, Lodish HF. Role of transforming growth factor beta in human disease. N Engl J Med 342: 1350-1358, 2000.

7. Borghi C, Veronesi M, Prandin MG, Dormi A, Ambrosioni E. Statins and blood pressure regulation. Curr Hypertens Rep 3: 281-288, 2001.

8. Brenner BM, Cooper ME, de Zeeuw D, Keane WF, Mitch WE, Parving HH, Remuzzi G, Snapinn SM, Zhang Z, Shahinfar S. Effects of losartan on renal and cardiovascular outcomes in patients with type 2 diabetes and nephropathy. $N$ Engl J Med 345: 861-869, 2001.

9. Bussolati B, Deregibus MC, Fonsato V, Doublier S, Spatola T, Procida S, Di Carlo F, Camussi G. Statins prevent oxidized LDL-induced injury of glomerular podocytes by activating the phosphatidylinositol 3-kinase/ AKT-signaling pathway. J Am Soc Nephrol 16: 1936-1947, 2005.

10. Carbajal JM, Schaeffer RC Jr. RhoA inactivation enhances endothelial barrier function. Am J Physiol Cell Physiol 277: C955-C964, 1999.

11. Cormack-Aboud FC, Brinkkoetter PT, Pippin JW, Shankland SJ, Durvasula RV. Rosuvastatin protects against podocyte apoptosis in vitro. Nephrol Dial Transplant 24: 404-412, 2009.

12. Dalla Vestra M, Masiero A, Roiter AM, Saller A, Crepaldi G, Fioretto P. Is podocyte injury relevant in diabetic nephropathy? Studies in patients with type 2 diabetes. Diabetes 52: 1031-1035, 2003.

13. Feldstein CA. Statins as antihypertensives. Recent Pat Cardiovasc Drug Discov 3: 92-97, 2008.

14. Gagliardini E, Corna D, Zoja C, Sangalli F, Carrara F, Rossi M, Conti S, Rottoli D, Longaretti L, Remuzzi A, Remuzzi G, Benigni A. Unlike each drug alone, lisinopril if combined with avosentan promotes regression of renal lesions in experimental diabetes. Am J Physiol Renal Physiol 297: F1448-F1456, 2009.

15. Gross ML, El-Shakmak A, Szabo A, Koch A, Kuhlmann A, Munter K, Ritz E, Amann K. ACE-inhibitors but not endothelin receptor blockers prevent podocyte loss in early diabetic nephropathy. Diabetologia 46: 856-868, 2003.

16. Heid HW, Moll R, Schwetlick I, Rackwitz HR, Keenan TW. Adipophilin is a specific marker of lipid accumulation in diverse cell types and diseases. Cell Tissue Res 294: 309-321, 1998.

17. Kelly DJ, Aaltonen P, Cox AJ, Rumble JR, Langham R, Panagiotopoulos S, Jerums G, Holthofer H, Gilbert RE. Expression of the slit-diaphragm protein, nephrin, in experimental diabetic nephropathy: differing effects of anti-proteinuric therapies. Nephrol Dial Transplant 17: 1327-1332, 2002.

18. Kunz R, Friedrich C, Wolbers M, Mann JF. Meta-analysis: effect of monotherapy and combination therapy with inhibitors of the renin angiotensin system on proteinuria in renal disease. Ann Intern Med 148: 30-48, 2008.

19. Langham RG, Kelly DJ, Cox AJ, Thomson NM, Holthofer H, Zaoui P, Pinel N, Cordonnier DJ, Gilbert RE. Proteinuria and the expression of the podocyte slit diaphragm protein, nephrin, in diabetic nephropathy: effects of angiotensin converting enzyme inhibition. Diabetologia 45: 1572-1576, 2002.

20. Lewis EJ, Hunsicker LG, Clarke WR, Berl T, Pohl MA, Lewis JB, Ritz E, Atkins RC, Rohde R, Raz I. Renoprotective effect of the angiotensin-receptor antagonist irbesartan in patients with nephropathy due to type 2 diabetes. $N$ Engl J Med 345: 851-860, 2001.

21. Macconi D, Bonomelli M, Benigni A, Plati T, Sangalli F, Longaretti L, Conti S, Kawachi H, Hill P, Remuzzi G, Remuzzi A. Pathophysiologic 
implications of reduced podocyte number in a rat model of progressive glomerular injury. Am J Pathol 168: 42-54, 2006.

22. Macconi D, Sangalli F, Bonomelli M, Conti S, Condorelli L, Gagliardini E, Remuzzi G, Remuzzi A. Podocyte repopulation contributes to regression of glomerular injury induced by ACE inhibition. Am J Pathol 174: 797-807, 2009.

23. Mann JF, Schmieder RE, McQueen M, Dyal L, Schumacher H, Pogue J, Wang X, Maggioni A, Budaj A, Chaithiraphan S, Dickstein K, Keltai M, Metsarinne K, Oto A, Parkhomenko A, Piegas LS, Svendsen TL, Teo KK, Yusuf S. Renal outcomes with telmisartan, ramipril, or both, in people at high vascular risk (the ONTARGET study): a multicentre, randomised, double-blind, controlled trial. Lancet 372: 547-553, 2008.

24. Marre M, Chatellier G, Leblanc H, Guyene TT, Menard J, Passa P. Prevention of diabetic nephropathy with enalapril in normotensive diabetics with microalbuminuria. Br Med J 297: 1092-1095, 1988.

25. Mason JC. The statins - therapeutic diversity in renal disease? Curr Opin Nephrol Hypertens 14: 17-24, 2005.

26. Meyer TW, Bennett PH, Nelson RG. Podocyte number predicts longterm urinary albumin excretion in Pima Indians with Type II diabetes and microalbuminuria. Diabetologia 42: 1341-1344, 1999.

27. Milionis HJ, Liberopoulos EN, Achimastos A, Elisaf MS, Mikhailidis DP. Statins: another class of antihypertensive agents? J Hum Hypertens 20: 320-335, 2006.

28. Mooradian AD, Haas MJ. Statins ameliorate glomerular permeability changes in streptozotocin-induced diabetic rats. Am J Ther 14: 41-45, 2007.

29. Morelli E, Loon NR, Meyer TW, Peters W, Myers BD. Effects of converting enzyme inhibition on barrier function in diabetic glomerulopathy. Diabetes 39: 76-82, 1990.

30. Parving HH. Diabetic nephropathy: prevention and treatment. Kidney Int 60: 2041-2055, 2001

31. Perico N, Amuchastegui SC, Colosio V, Sonzogni G, Bertani T, Remuzzi G. Evidence that an angiotensin-converting enzyme inhibitor has a different effect on glomerular injury according to the different phase of the disease at which the treatment is started. J Am Soc Nephrol 5: 1139-1146, 1994

32. Perico N, Benigni A, Remuzzi G. Present and future drug treatments for chronic kidney diseases: evolving targets in renoprotection. Nat Rev Drug Discov 7: 936-953, 2008

33. Ravid M, Lang R, Rachmani R, Lishner M. Long-term renoprotective effect of angiotensin-converting enzyme inhibition in non-insulin-dependent diabetes mellitus. A 7-year follow-up study. Arch Intern Med 156: 286-289, 1996.

34. Reeves WB, Andreoli TE. Transforming growth factor beta contributes to progressive diabetic nephropathy. Proc Natl Acad Sci USA 97: 76677669,2000 .

35. Remuzzi A, Gagliardini E, Sangalli F, Bonomelli M, Piccinelli M, Benigni A, Remuzzi G. ACE inhibition reduces glomerulosclerosis and regenerates glomerular tissue in a model of progressive renal disease. Kidney Int 69: 1124-1130, 2006

36. Remuzzi A, Perico N, Amuchastegui CS, Malanchini B, Mazerska M, Battaglia C, Bertani T, Remuzzi G. Short- and long-term effect of angiotensin II receptor blockade in rats with experimental diabetes. $J$ Am Soc Nephrol 4: 40-49, 1993.

37. Remuzzi G, Bertani T. Pathophysiology of progressive nephropathies. $N$ Engl J Med 339: 1448-1456, 1998.

38. Remuzzi G, Schieppati A, Ruggenenti P. Nephropathy in patients with type 2 diabetes. $N$ Engl J Med 346: 1145-1151, 2002.
39. Rippe C, Rippe A, Torffvit O, Rippe B. Size and charge selectivity of the glomerular filter in early experimental diabetes in rats. Am J Physiol Renal Physiol 293: F1533-F1538, 2007.

40. Rizki G, Arnaboldi L, Gabrielli B, Yan J, Lee GS, Ng RK, Turner SM, Badger TM, Pitas RE, Maher JJ. Mice fed a lipogenic methioninecholine-deficient diet develop hypermetabolism coincident with hepatic suppression of SCD-1. J Lipid Res 47: 2280-2290, 2006.

41. Ruggenenti P, Mosconi L, Sangalli F, Casiraghi F, Gambara V, Remuzzi G, Remuzzi A. Glomerular size-selective dysfunction in NIDDM is not ameliorated by ACE inhibition or by calcium channel blockade. Kidney Int Suppl 55: 984-994, 1999.

42. Ruggenenti P, Perticucci E, Cravedi P, Gambara V, Costantini M, Sharma SK, Perna A, Remuzzi G. Role of remission clinics in the longitudinal treatment of CKD. J Am Soc Nephrol 19: 1213-1224, 2008.

43. Ruggenenti P, Remuzzi G. Proteinuria: is the ONTARGET renal substudy actually off target? Nat Rev Nephrol 5: 436-437, 2009.

44. Ruggenenti P, Schieppati A, Remuzzi G. Progression, remission, regression of chronic renal diseases. Lancet 357: 1601-1608, 2001.

45. Sakharova OV, Taal MW, Brenner BM. Pathogenesis of diabetic nephropathy: focus on transforming growth factor-beta and connective tissue growth factor. Hypertension 10: 727-738, 2001

46. Shankland SJ. The podocyte's response to injury: role in proteinuria and glomerulosclerosis. Kidney Int 69: 2131-2147, 2006.

47. Shibata S, Nagase M, Fujita T. Fluvastatin ameliorates podocyte injury in proteinuric rats via modulation of excessive Rho signaling. J Am Soc Nephrol 17: 754-764, 2006.

48. Susztak K, Raff AC, Schiffer M, Bottinger EP. Glucose-induced reactive oxygen species cause apoptosis of podocytes and podocyte depletion at the onset of diabetic nephropathy. Diabetes 55: 225-233, 2006.

49. Tibolla G, Norata GD, Meda C, Arnaboldi L, Uboldi P, Piazza F, Ferrarese C, Corsini A, Maggi A, Vegeto E, Catapano AL. Increased atherosclerosis and vascular inflammation in APP transgenic mice with apolipoprotein E deficiency. Atherosclerosis 210: 78-87, 2010.

50. Tryggvason K, Wartiovaara J. Molecular basis of glomerular permselectivity. Curr Opin Nephrol Hypertens 10: 543-549, 2001.

51. Weibel E. Stereological methods. In: Practical Methods for Biological Morphometry. London: Academic, 1979, p. 40-116.

52. Whaley-Connell A, Habibi J, Nistala R, Cooper SA, Karuparthi PR, Hayden MR, Rehmer N, DeMarco VG, Andresen BT, Wei Y, Ferrario C, Sowers JR. Attenuation of NADPH oxidase activation and glomerular filtration barrier remodeling with statin treatment. Hypertension 51: $474-$ 480, 2008.

53. White KE, Bilous RW, Marshall SM, El Nahas M, Remuzzi G, Piras G, De Cosmo S, Viberti G. Podocyte number in normotensive type 1 diabetic patients with albuminuria. Diabetes 51: 3083-3089, 2002.

54. Wild S, Roglic G, Green A, Sicree R, King H. Global prevalence of diabetes: estimates for the year 2000 and projections for 2030. Diabetes Care 27: 1047-1053, 2004.

55. Wolf G, Chen S, Ziyadeh FN. From the periphery of the glomerular capillary wall toward the center of disease: podocyte injury comes of age in diabetic nephropathy. Diabetes 54: 1626-1634, 2005.

56. Wolf G, Ritz E. Combination therapy with ACE inhibitors and angiotensin II receptor blockers to halt progression of chronic renal disease: pathophysiology and indications. Kidney Int 67: 799-812, 2005.

57. Zoja C, Corna D, Camozzi D, Cattaneo D, Rottoli D, Batani C, Zanchi C, Abbate M, Remuzzi G. How to fully protect the kidney in a severe model of progressive nephropathy: a multidrug approach. J Am Soc Nephrol 13: 2898-2908, 2002. 